\title{
EHR access and training still lacking for medical trainees
}

n Cite as: CMAJ 2018 September 4;190:E1054. doi: 10.1503/cmaj.109-5650

Posted on cmajnews.com on Aug. 14, 2018.

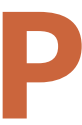

hysicians have plenty of complaints about the shortcomings of electronic health records (EHR), such as lack of interoperability, but not all technology problems can be blamed on software. Sometimes the user is largely to blame for suboptimal EHR use, particularly if that user is a first-year medical resident.

According to the American Medical Association, medical schools and residency programs are not adequately preparing trainees to use EHRs, and a lack of familiarity with these systems is preventing first-year residents from using their time optimally. Many medical institutions restrict who can use EHRs, and trainees are often denied access. But workarounds to restrictions are needed to solve this problem, according to Karthik Sarma, a medical student and board member of the association: "There is a clear need for medical students to have access to - and learn how to use properly - EHRs well before they enter practice."

At its recent annual meeting, the association adopted a new policy to call upon medical schools and residency programs to design clinical documentation and EHR training with evaluative feedback and to provide professional development resources for faculty, so they can model appropriate EHR use during patient interactions.

Inadequate EHR training has been an issue in medical education in Canada and the United States for some time. A 2009 survey of internal medicine programs in Canadian and American clinical institutions found that only $44 \%$ had policies about trainees accessing EHRs to document clinical encounters. More than half of respondents (52\%) said their programs prohibited trainees from accessing EHRs,

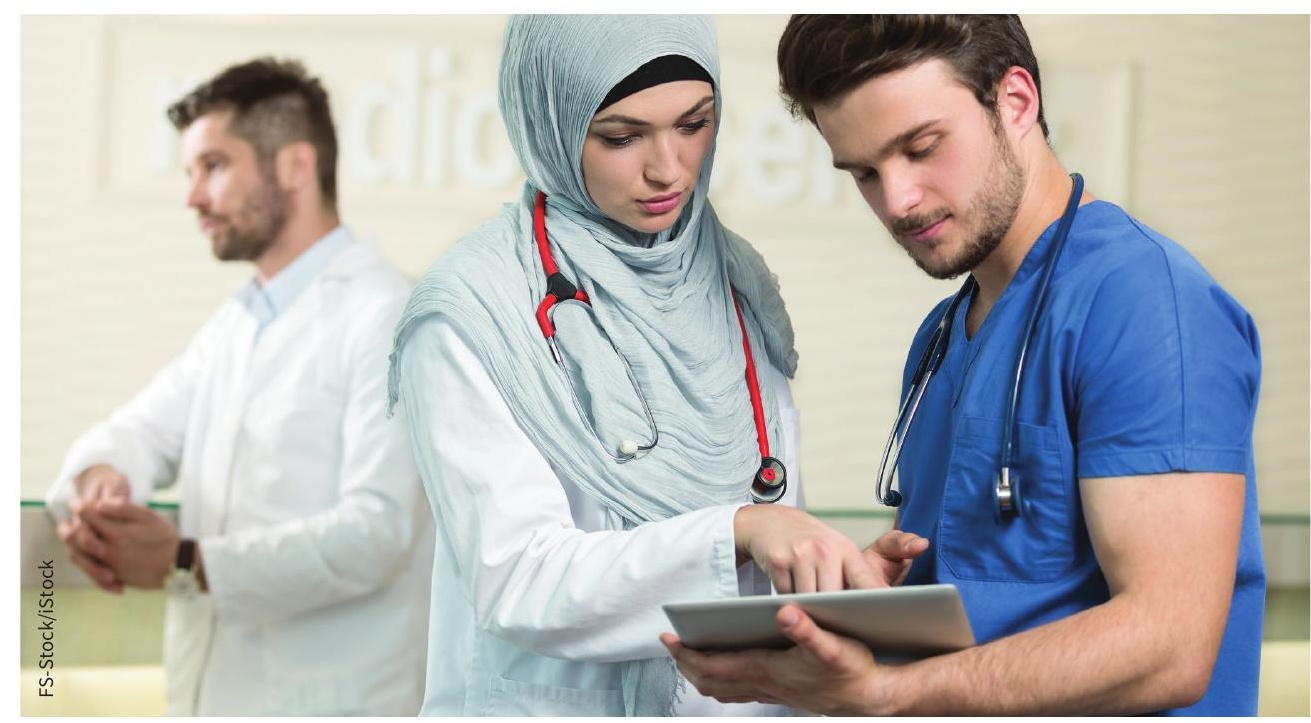

Some clinical institutions restrict or limit medical trainee access to EHRs.

primarily over concerns about billing and note quality.

By 2012, according to an American survey, about $64 \%$ of US clerkship programs allowed medical students to access EHRs, although only two-thirds of those programs permitted students to enter notes. Clinical institutions with trainees "need to explore ways to maximize the benefits of electronic health records in medical education," the authors concluded. That same year, the US-based Alliance for Clinical Education called upon medical education institutions to develop guidelines to establish expectations for student training on using EHRs. The group recommended that medical schools "develop a clear set of competencies" on EHR use that students "must achieve prior to graduation in order to ensure they are ready for clinical practice."

To improve education on EHRs and other technologies in Canada, the Asso- ciation of Faculties of Medicine of Canada (AFMC) partnered with Canada Health Infoway in 2014 to create competitions to encourage "medical school faculty, students and residents in their learning and clinical use of digital tools." On Feb. 23 of this year, AFMC and Infoway announced another initiative that would support "medical students and residents in their adoption and use of information and communication technologies, such as electronic medical records." The project will include the creation of curriculum-based resources, e-learning tools, virtual patient challenges for students, and annual awards for "leaders who advance medical informatics in education and learning opportunities related to electronic health record systems."

Roger Collier, CMAJ 